\title{
BIOLOGÍA
}

\section{Análisis de la herpetofauna asociada a los Humedales del Complejo Ypoá}

\author{
Karina Núñez ${ }^{1}$, Andrea Weiler¹, Griselda Zárate1 , Johanna López¹, \\ Rodrigo Ayala ${ }^{1}$, María Vera ${ }^{1}$
}

\section{Resumen}

Introducción: Los humedales son ecosistemas en los cuales el agua es el principal factor controlador del medio y la vida vegetal y animal asociada a él. Constituyen cunas de diversidad biológica y fuentes acuíferas y productividad primaria de las que innumerables especies dependen para subsistir. Dan sustento a altas concentraciones de aves, mamíferos, reptiles, anfibios, peces e invertebrados. Brindan numerosos servicios ecosistémicos, tales como almacenamiento y purificación del agua dulce, regulación de la erosión, mitigación de inundaciones, regulación de la calidad del aire, del clima y regímenes hidrológicos. Además, constituyen sitios potenciales para el desarrollo de turismo de naturaleza, con oportunidad de inclusión de las comunidades locales. Los humedales paraguayos se integran al sistema general de formas de paisaje intercratónico del área subamazónica sudamericana. Se encuentran asociados principalmente a los ríos Paraná, Paraguay, Pilcomayo, Apa, Negro y al arroyo Estrella. El presente estudio se centra en los humedales del complejo Ypoá, ubicados en la región Oriental del Paraguay. Poseen áreas elevadas y depresiones que forman las lagunas Cabral, Verá e Ypoá, las cuales se encuentran ligadas por extensos esterales. Su cuenca es regada por numerosos cursos de agua, tributarios del río Paraguay, destacándose el arroyo Caañabé y el río Tebicuary. Debido a su importancia internacional en términos ecológicos, botánicos, zoológicos, limnológicos e hidrológicos, el complejo de humedales del Ypoá fue declarado en 1995 como sitio RAMSAR. Investigaciones sobre las comunidades vegetales en el área han evidenciado la rica diversidad de hábitats que posee, no obstante, la fauna ha sido escasamente estudiada. El presente trabajo se enfoca en el estudio de la herpetofauna asociada a dichos humedales, en la cual se incluye a la clase Amphibia, representada por ranas, sapos, cecilias y salamandras, y la clase Reptilia, a la cual pertenecen los lagartos, serpientes, caimanes y tortugas. Algunas características de los anfibios son su dependencia al agua y humedad, ciclos de vida complejos, y sensibilidad fisiológica a condiciones ambientales debido a que poseen una piel muy permeable. Por su parte, los reptiles son vertebrados ectotermos, tetrápodos exceptuando las serpientes, que poseen varias adaptaciones para la vida en el medio terrestre. Se caracterizan por tener

1. Departamento de Biología. Colección Zoológica -CZCEN. Facultad de Ciencias Exactas y Naturales -FACEN-, Universidad Nacional de Asunción, Paraguay.

Proyecto financiado por el Programa PROCIENCIA- CONACYT, PINV15-820.

E-mail: ranitapy@gmail.com

DOI: 10.26885/rcei.foro.2017.18 


\section{Análisis de la herpetofauna asociada a los Humedales del Complejo Ypoá. Núnez et al.}

la piel fuertemente queratinizada y cubierta por escamas córneas duras y secas, que los protegen de la desecación y los depredadores.

Objetivo: Caracterizar la herpetofauna asociada a los humedales del complejo Ypoá y difundir los resultados a fin de lograr una valoración social. Los objetivos específicos son (1) identificar los tipos de hábitats presentes en los humedales del complejo Ypoá (2) determinar la composición, riqueza y abundancia de anfibios y reptiles en los distintos hábitats del área de estudio (3) analizar la ocurrencia de especies en relación a variables ambientales (4) fomentar el conocimiento sobre la herpetofauna y las funciones ecológicas de los humedales del complejo Ypoá (5) aportar conocimiento específico sobre la herpetofauna que sirva de base para la elaboración del plan de manejo de la Reserva de Recursos Manejados Lago Ypoá.

Material y Método: Se realizará una visita preliminar con el objetivo de identificar las formaciones vegetales, la elección de los sitios de muestreo y la adecuación de las técnicas para la colecta de datos. Posteriormente, se efectuarán visitas periódicas a tres sitios asociados a los humedales del complejo Ypoá. En los mismos se empleará el método de relevamiento por encuentro visual (VES), en horarios diurnos y nocturnos, con la finalidad de registrar los ejemplares de anfibios y reptiles vistos y escuchados del área. Dicha técnica será complementada con cercas en línea recta y trampas pozo. Los ejemplares capturados serán fotografiados y se tomarán datos de las variables morfométricas. A modo de formar la colección testigo del área, algunos individuos serán sacrificados. Los mismos serán depositados en la Colección Zoológica de la Facultad de Ciencias Exactas y Naturales (CZCEN). Todos los datos serán analizados estadísticamente, con índices de diversidad, curvas de acumulación y análisis de ordenación de comunidades. Con la finalidad de fomentar el conocimiento acerca de los servicios ecosistémicos proveídos por los humedales y la diversidad e importancia de anfibios y reptiles del área estudiada se realizarán charlas en escuelas, colegios y universidades ubicadas principalmente en las zonas de influencia del lago Ypoá.

Palabras clave: herpetofauna, Humedales del Complejo Ypoá.

\section{RefERENCIAS}

Heyer, W., Donnelly, M., McDiarmid, W. \& Foster, M. (Eds.). (sf). Medición y monitoreo de la diversidad biológica: Métodos estandarizados para anfibios. sl: Editorial Universitaria de la Patagonia.

Mereles, F., Degen, R. \& López, N. (1992). Humedales en el Paraguay: breve reseña de su vegetación. Amazonia, 12(2), 305- 316.

Mereles, F. (2005). Aportes al conocimiento de la Flora y las comunidades vegetales en la cuenca del lago Ypoá, Región Oriental, Paraguay. INSUGEO, Miscelánea, (14), 159-68.

RAMSAR. (2013). Manual de la Convención de RAMSAR: guía a la Convención sobre los humedales (6 ed.). Gland: sn. 